editorial

3 Die Wahl der optimalen Therapie ist komplizierter geworden!

"Gute alte Zeiten, als jedes Ding nur zwei Seiten hatte!" Martin Dreyling

journal club

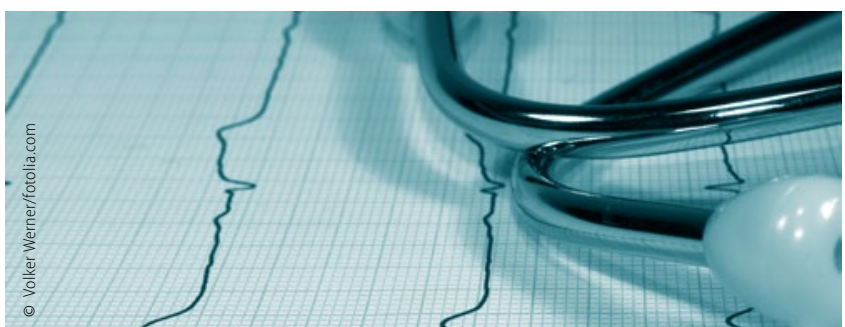

10 Radiotherapie bei Mammakarzinom

Risiko für Herzinfarkt erhöht Erhard Hiller

\section{Metastasiertes Mammakarzinom}

Antiöstrogene Kombination verbessert Gesamtüberleben Nikolaus de Gregorio, Wolfgang Janni

15 Therapie des metastasierten malignen Melanoms

Elesclomol in Phase III geprüft Andreas Schalhorn

\section{Erst praktiziert, jetzt validiert}

Bendamustin plus Rituximab als Erstlinienbehandlung indolenter Lymphome Georg Heß
20 Radiochemotherapie beim Nasopharynxkarzinom

Welche prognostische Bedeutung hat die Cisplatin-Dosis? Hans Christiansen, Hendrik Andreas Wolff

\section{Schmerzhafte Wirbelkörpermetastasen}

Vorteile der stereotaktischen gegenüber der konventionellen Bestrahlung

Dirk Rades

\section{Low-Grade-Gliome}

Radiotherapie mit Polychemotherapie intensivieren? Gerhard G. Grabenbauer

zertifizierte fortbildung

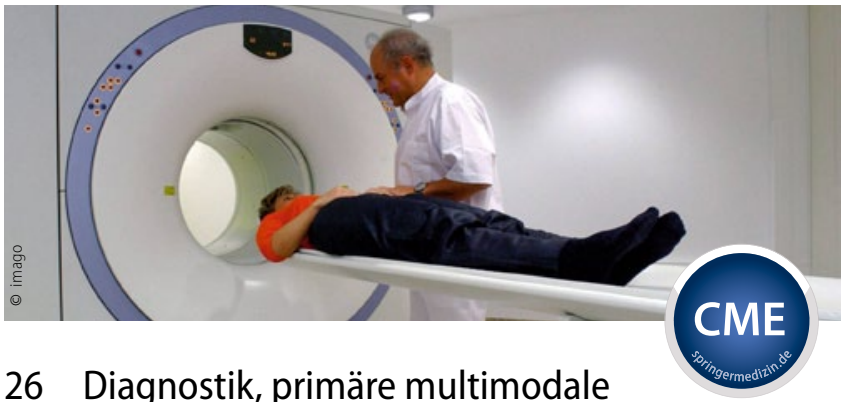
Therapie und Nachsorge

Lokales und lokal fortgeschrittenes Magenkarzinom Frank Zimmermann, Florian Lordick

\section{CME Fragen}

\section{Vorankündigung}

In Heft 5/2013 der InFo Onkologie erscheint eine CME-Fortbildung zum Thema "extragonale Keimzelltumoren"

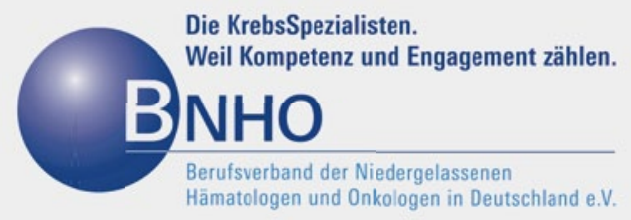

Kontakt:

Sachsenring 57

50677 Köln

Tel.: 02219987980

Fax: 022199879822

Geschäftsführung: Armin Goetzenich 
onkologie aktuell

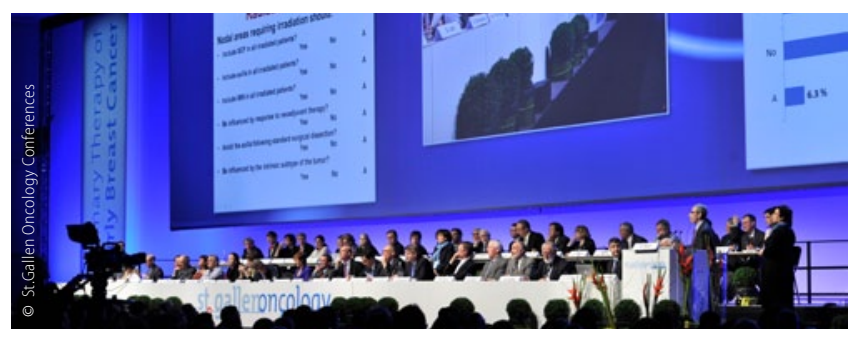

34 Prof. Sibylle Loibl zu den Ergebnissen der 13. St.-Gallen-Konferenz

„Es gibt keine absolute Kontraindikation zur brusterhaltenden Operation" neues aus der forschung

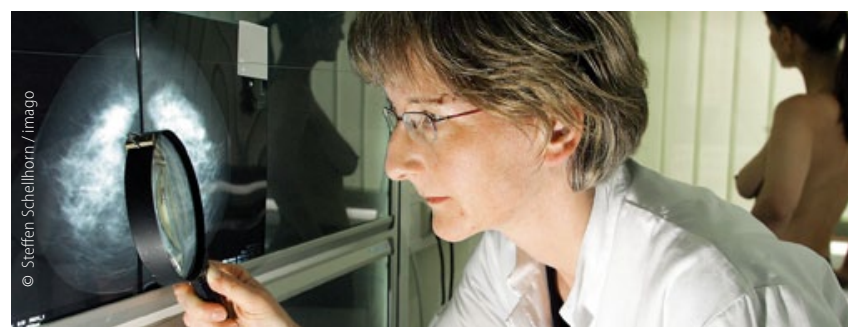

\section{Trends und Daten aus der Onkologie}

Beruhigende Daten: Schwangerschaft verschlechtert nicht Prognose bei Brustkrebs

Rezidivierte akute Leukämie: Immuntherapie schafft Brücke zur lebensrettenden Stammzelltransplantation

MRT-Studie: ALL im Kindesalter hinterlässt Spuren im Gehirn

Postoperative Sterberate nach Darmkrebs-Operation: Erhöhte Mortalität bei Leberzirrhotikern

rubriken

$44 \operatorname{In} \mid$ Fo|Pharm

47 Editorial Board | Impressum | Kontakt 